\title{
Laparoscopic Adrenalectomy for Isolated Adrenal Metastasis: The Right Thing to Do and the Right Way to Do It
}

\author{
Quan-Yang Duh, MD
}

Surgical Service, VA Medical Center, 4150 Clement Street, San Francisco, CA 94121, USA

Long-term survival after resection of isolated adrenal metastatic was first reported in 1982 by Twomey et al. ${ }^{1}$ Their two patients were disease-free for 6 and 14 years after resection of an isolated adrenal metastasis from large-cell lung cancer. Since then, many series, including several from the Memorial Sloan-Kettering Cancer Center, have confirmed that when metastasis is isolated to the adrenal gland, adrenalectomy can achieve long-term survival. In "Laparoscopic Adrenalectomy for Isolated Adrenal Metastasis", Strong et al. ${ }^{2}$ updated the results of the series from Memorial Sloan-Kettering Cancer Center, last published in 2003 with 41 patients and 11 laparoscopic adrenalectomies. ${ }^{3,4}$ The current report of 94 adrenalectomies (31 laparoscopic) in 92 patients more than doubled their previous report and is the largest series published to date to addresses this issue.

So what is new? With such a large number of patients, Strong et al. were able to more definitively compare the results of laparoscopic adrenalectomy versus open adrenalectomy. They showed that laparoscopic adrenalectomy, compared with open adrenalectomy, resulted in less morbidity and achieved similar oncological outcomes.

It is not surprising that laparoscopic resection results in less morbidity; there is less blood loss, fewer complications, and a shorter hospital stay. These findings are consistent with other smaller series ${ }^{5-8}$

Received July 16, 2007; accepted July 17, 2007; published online: September 25, 2007.

Address correspondence and reprint requests to: Quan-Yang Duh, MD; E-mail: DuhQ@surgery.ucsf.edu

Published by Springer Science+Business Media, LLC ๔ 2007 The Society of Surgical Oncology, Inc. and are consistent with the results of other types of laparoscopic operations compared with open operations, including cholecystectomy, splenectomy, nephrectomy, and colectomy. One potential confounding variable in this study is the size of tumor; the mean size of tumor was $3.8 \mathrm{~cm}$ for the laparoscopic adrenalectomy group versus $6.4 \mathrm{~cm}$ for the open adrenalectomy group. The authors addressed this potential problem by a subgroup analysis limiting the comparison to only patients with tumors $<4.5 \mathrm{~cm}$. This subgroup analysis showed that the advantages of laparoscopic resection persisted, so smaller-size tumors did not explain the better results of laparoscopic operation. The shorter operation time for laparoscopic resection - almost half an hour shorter than for open resection-most likely reflected the experience of the Memorial Sloan-Kettering surgeons, who were already beyond their initial learning curve for laparoscopic adrenalectomy.

When operating for cancers, the most important concern for patients and surgeons is whether laparoscopic resection can achieve the same oncological outcomes as the more morbid open resection. In the case of laparoscopic adrenalectomy, the outcomes that could potentially be affected are the risk of local recurrence and the chance of long-term survival. In this series, neither was adversely affected by laparoscopic adrenalectomy. The local recurrence rates of $11 \%$ for laparoscopic adrenalectomy and $21 \%$ for open adrenalectomy are not different than other series that showed either no local recurrences ${ }^{5,6}$ or a local regional recurrence rate of about $20 \%{ }^{7,8}$ after laparoscopic resection for an isolated adrenal metastasis. Port-site recurrence is rare, ${ }^{9}$ and there 
were none in this study. Overall, the risk of local or port site recurrence is much lower after laparoscopic adrenalectomy for metastasis than that for primary adrenal cortical cancer. This is likely the result of different cancer biology and the more central location and firmer consistency of adrenal metastases, making it less likely that the laparoscopic surgeon will breach the capsular and rupture the tumor.

One interesting finding in this series is that the best independent predictor of patient survival was smaller tumor size. Long-term survival rate was twice as high for patients with metastases $<4.5 \mathrm{~cm}$ than for those with metastases $>4.5 \mathrm{~cm}$ (58\% vs. $29 \%$ for 3 -year survival and $40 \%$ vs. $22 \%$ for 5 -year survival). Tumor size tends to predict survival in many primary cancers; why it should also predict survival in patients with isolated adrenal metastasis is not clear. Do the smaller metastases reflect less aggressive cancer or just earlier discovery? We do not know.

Another interesting finding in this series is that the disease-free interval between the discovery of primary cancer and the development of metastasis was not a predictor for survival. This is in contrast to the conclusion drawn from their previous smaller series, which showed that patients with metachronous metastasis had better survival than those with synchronous metastasis. ${ }^{3}$ Perhaps the current, more sensitive imaging studies helped exclude most patients with extra-adrenal metastases who would be expected to have a poorer prognosis.
It is now 25 years after the first report of long-term survival after resection of isolated adrenal metastasis and 15 years after the first description of laparoscopic adrenalectomy. This study by Strong et al. shows us that adrenalectomy for isolated adrenal metastasis is the right thing to do, and that laparoscopic adrenalectomy is the right way to do it.

\section{REFERENCES}

1. Twomey P, Montgomery C, Clark O. Successful treatment of adrenal metastases from large-cell carcinoma of the lung. JAMA 1982; 248:581-3.

2. Strong V, D’Angelica M, Tang L, et al. (2007) Laparoscopic adrenalectomy for isolated adrenal metastasis. Ann Surg Oncol 14; doi: 10.1245/s10434-007-9520-7 [Online July 31, 2007].

3. Sarela AI, Murphy I, Coit DG, Conlon KC. Metastasis to the adrenal gland: the emerging role of laparoscopic surgery. Ann Surg Oncol 2003; 10:1191-6.

4. Duh QY. Resecting isolated adrenal metastasis: why and how? Ann Surg Oncol 2003; 10:1138-9.

5. Kebebew E, Siperstein AE, Clark OH, Duh QY. Results of laparoscopic adrenalectomy for suspected and unsuspected malignant adrenal neoplasms. Arch Surg 2002; 137:948-53.

6. Adler JT, Mack E, Chen H. Equal oncologic results for laparoscopic and open resection of adrenal metastases. J Surg Res 2007; 140:159-64

7. Moinzadeh A, Gill IS. Laparoscopic radical adrenalectomy for malignancy in 31 patients. $J$ Urol 2005; 173:519-25.

8. Lucchi M, Dini P, Ambrogi MC, et al. Metachronous adrenal masses in resected non-small cell lung cancer patients: therapeutic implications of laparoscopic adrenalectomy. Eur $J$ Cardiothorac Surg 2005; 27:753-6.

9. Weyhe D, Belyaev O, Skawran S, Muller C, Bauer KH. A case of port-site recurrence after laparoscopic adrenalectomy for solitary adrenal metastasis. Surg Laparosc Endosc Percutan Tech 2007; 17:218-20. 